\title{
Slope design at Mt Rawdon gold mine
}

\author{
R Jele Evolution Mining, Australia \\ T Sullivan Pells Sullivan Meynink and The University of New South Wales, Australia
}

\begin{abstract}
This paper deals at a practical level with the evolution of slope designs at Mt Rawdon gold mine. The focus of the paper is on the interaction between rock structure, mine equipment, final wall blasting practices and bench design. The aim of the paper is to illustrate the important technical facets and the engineering design solutions developed to achieve steep overall pit walls in difficult conditions, while focussing on maintaining stability and safety.
\end{abstract}

\section{Introduction}

Mt Rawdon is located $270 \mathrm{~km}$ northwest of Brisbane and $70 \mathrm{~km}$ west-southwest of Bundaberg. The nearest town is Mount Perry, a distance of $20 \mathrm{~km}$ away.

Mt Rawdon open pit is a relatively mature operation and there have been a number of different owners. This has resulted in many different slope design approaches and a number of iterations of slope stability design work. This is an important characteristic, from a geotechnical perspective, of many small to medium scale mining operations, funding is often limited for engineering studies, frequently more regional resources are utilised for studies and at the same time there are often strong pressures to reduce mining costs. The mine is not a high grade operation and economic pressures underlie most technical decisions. In that context, the Mt Rawdon open pit is currently undergoing a further redesign and optimisation. The pit will be extended from its current $290 \mathrm{~m}$ depth to $380 \mathrm{~m}$ and new pit slopes are required. This paper presents the process for evaluation of the data, the analyses and the conceptual logic behind the recommendations for the optimised pit slopes.

\section{$2 \quad$ Physical setting}

\subsection{Regional geology}

The Mt Rawdon gold Au-Ag deposit is hosted in rocks inferred to be equivalent to the Late Triassic Aranbanga Volcanic Group that unconformably overlies metamorphosed sedimentary rocks of the Carboniferous to Permian Curtis Island Group. Regional maps show the deposit is localised at, or near, the base of the Aranbanga Volcanic Group at the juncture of north-south and northeast-southwest trending faults (Figure 1). At Mt Rawdon, the Aranbanga Volcanic Group host rocks have been variously interpreted as being: vent-facies agglomerate with coeval sub-volcanic intrusives (Hewett 1984), post-dacitic porphyry agglomerate (Cayzer \& Leckie 1987), bedded subaerial pyroclastic flow, surge and ash-fall deposits intruded by coeval dacitic bodies (Gallo et al. 1990), various lapilli-facies fragmental units within a diatreme (Brooker 1991; Brooker \& Jaireth 1995), volcaniclastics intruded by coeval dacitic intrusions (Angus 1999 and l'Ons therein), and more recently a polymict pumice bearing breccia (Harris 2010).

This regional geological setting describes quite a complex volcanic and igneous history. That history is clearly linked with the occurrence of the gold deposit in this location. However that complexity and history adds to the slope design challenges. Geological settings for mining projects are almost always described as complex. The essence at the start of any slope design process is to carefully differentiate between a geological complexity and a complexity that has real engineering significance. 


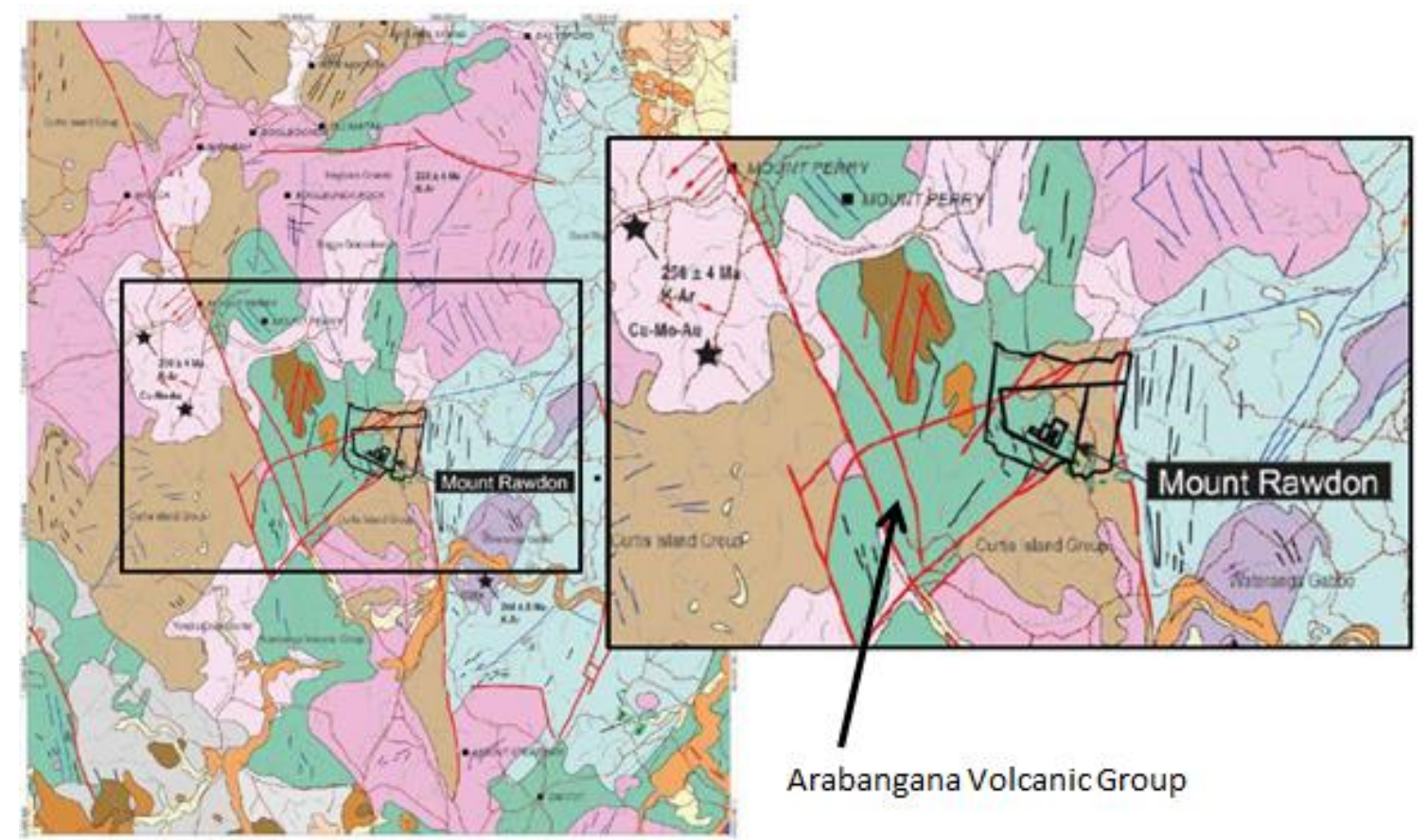

Figure 1 Regional geology map showing the location of Mt Rawdon with respect to the Aranbanga Volcanic Group and the Curtis Island Group both as labelled. Inset is a close-up of the Mount Perry/Mt Rawdon area showing the irregular outline of the base of the Aranbanga Volcanic Group at Mt Rawdon

\section{$2.2 \quad$ Local geology}

The Aranbanga Volcanic Group rocks in the Mt Rawdon pit comprise of matrix-supported, polymictic conglomerate with clasts ranging from angular to rounded, and in size from pebble to boulder, with pebble-cobble most common. Rarely are clast-supported conglomerates noted. Clasts have a wide variety of compositions, ranging from volcanic rocks (ash-rich, pumice-rich as would be expected from erosion of a volcanic sequence), through porphyritic volcanic and hypabyssal rocks, to basement rocks (granitoids, quartz, metasediments etc.), with the latter being most rounded. The matrix is mostly sand and grit sized. Sandstone and gritstone beds are uncommon, being restricted to the southern end of the pit immediately above down-thrown blocks of Eastern Dacite. Silt or ash beds were not encountered in the mapping.

None of these rocks are diagnostic of diatreme or vent facies, and realistically any basin marginal to an eroding volcanic arc (active or not) of any age will produce similar rocks to those seen at Mt Rawdon. The alternative interpretation promoted here is that the Aranbanga Volcanic Group rocks at Mt Rawdon is a reworked mixture of volcanics and volcaniclastics and 'basement' rocks mixed together in a high energy aqueous environment, most likely in turbidity canyon or fan setting. It may be that the 'embayment' like shape of the Aranbanga at Mt Rawdon is preservation of a canyon like feature, rather than a pure structural intersection. The Good Night Beds to the east could be the distal turbidite fans associated with the more proximal Aranbanga Volcanic Group.

Intruded into the Aranbanga Volcanic Group sediments are a myriad of intrusions, most commonly emplaced as dykes, but also plugs and stocks. These have a complex evolution relative to alteration, gold mineralisation, and fault deformation, with one another, as illustrated in Figure 2. 


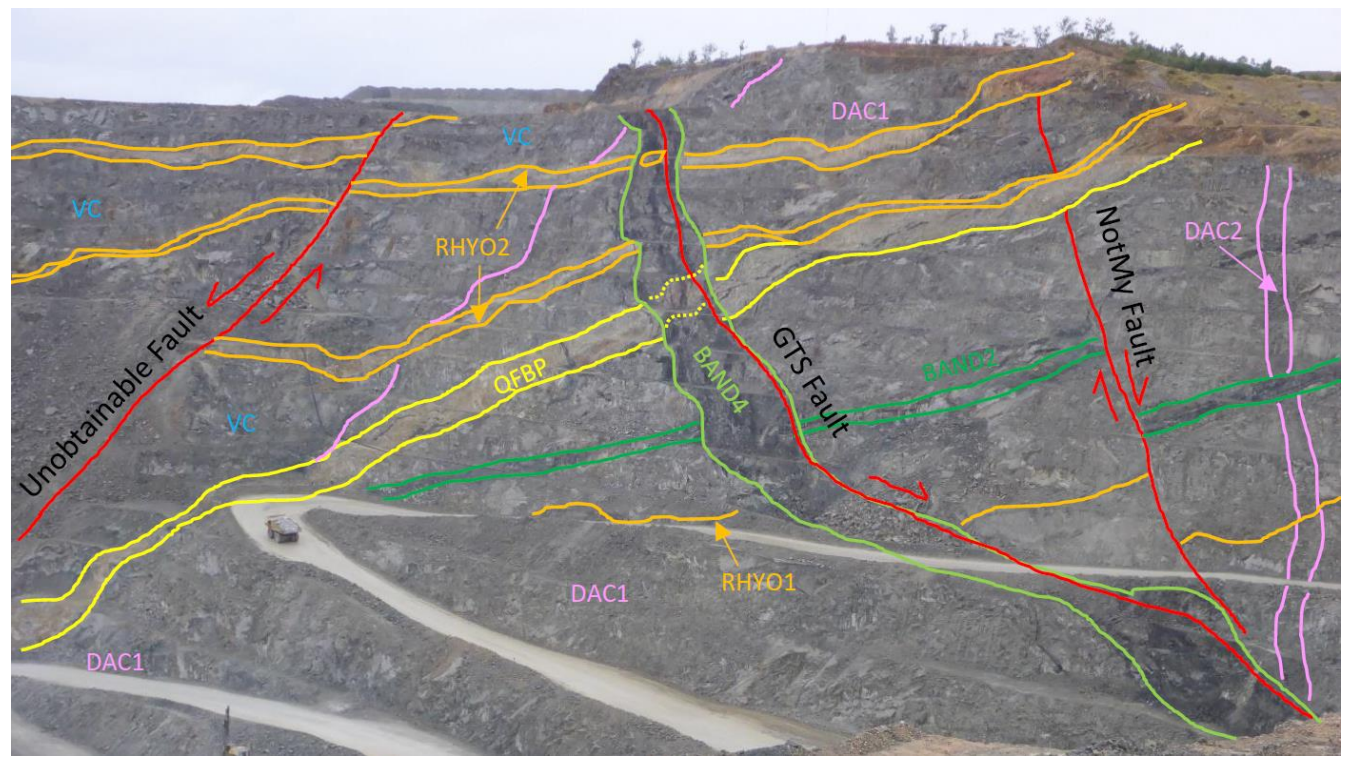

Figure 2 Panorama of the eastern wall of the Stage 3 pit, Mt Rawdon, showing overprinting relationships between GTS Fault, NotMy Fault, Unobtainable Fault, DAC1, DAC2, BAND2, BAND3, QFBP, RHYO1 and RHYO2 dykes. Clearly normal movement on the NotMy Fault occurred prior to the intrusion of QFBP dyke but after the intrusion of BAND2 dykes. Movement on GTS Fault has been minimal since the intrusion of QFBP and RHYO2 dykes

\subsection{Geological structure}

There are five major faults in the Mt Rawdon pit, all are steep dipping: the north-south striking GTS Fault and the Briggs-St John Fault, the northwest-southeast striking Angus and Tower Faults, and the northeast-southwest striking NotMy Fault (Figures 2 and 3).

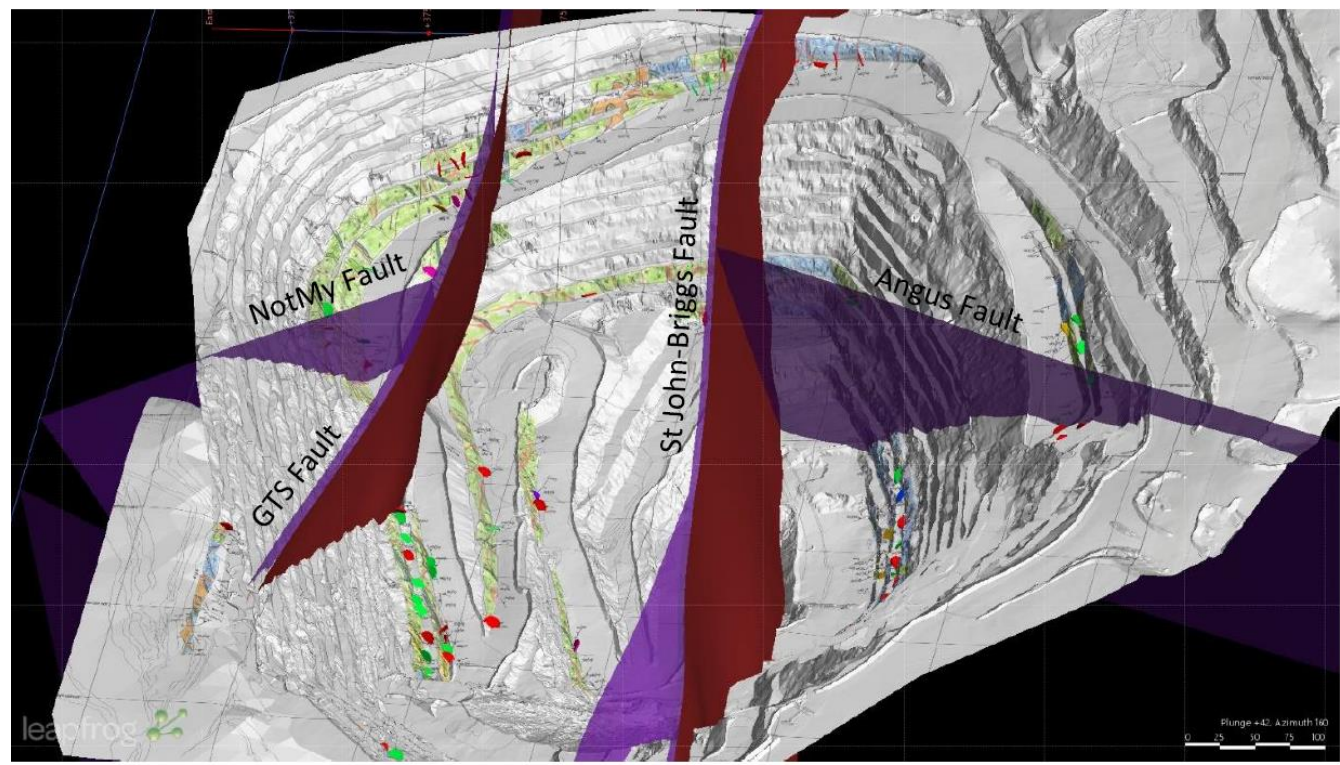

Figure 3 Mt Rawdon open pit, looking south showing digital terrain model and surfaces of the major mine scale faults in the pit

The majority of the faults display vertical normal movements, although the Tower Fault is an oblique dextral fault. The majority of the movements have occurred post-gold mineralisation, however, they have had little effect on the youngest dykes. Recorded kinematics, as determined from the offset of dykes, may not be representative of the bulk movement on the main faults. Minimal fault movement has occurred on any fault since the intrusion of the QFBP dyke (Figure 2). 


\section{Hydrogeology}

The local hydrogeology is characterised by generally tight basement rocks, which are variably faulted and broadly fractured, with some local more fractured zones. The recorded groundwater levels prior to mining were moderately shallow, 20 to $15 \mathrm{~m}$ below ground, and sub-parallel to the ground surface. This is also supported by reported low yields in most bores drilled over the site. Hence the pit walls are generally observed to be dry with minor local seeps and sump pumping requirement is low during the dry season (around 2 to $3 \mathrm{~L} / \mathrm{s}$ ).

However in these conditions the concern is for groundwater pressure impacts and the larger scale of the pit, particularly for the east wall with its particular structural pattern (Figure 2).

\section{$4 \quad$ Slope design process}

\subsection{Background challenges}

Any consideration of mine slope design must start with an understanding of the framework because this influences all of the qualitative and quantitative judgement decisions required in the slope design process. The background to this operation is:

- The mine has been in operation for 14 years and is a mature operation.

- There have been many different owners, each with their own unique approach to geotechnical engineering.

- The mine started out by excavating hills, small pits of limited depth and only over the last few years have significant pits been developed.

- The mining environment has changed significantly with a $380 \mathrm{~m}$ deep pit and aggressive inter-ramp slopes up to $60^{\circ}$.

- Because of these factors, final wall design and excavation practices are still in development.

- The technical data collected by each owner was different, each with its own issues and questions around degree of sampling of the natural population for each parameter, biases, representativeness and reliability.

\subsection{Geotechnical setting}

Because Mt Rawdon is a mature operation, large exposures of most rock mass units and structures are available. The fundamental geotechnical challenge is, therefore, not to undertake a formulaic approach to the slope design, by simply following a slope design guideline and making sure all the boxes are populated. In the challenging economic environment, which faces many small to medium scale mines, this approach is generally not appropriate, successful or possible.

However, wide experience has demonstrated that once an adequately large exposure of the rocks is available then the keys for a successful slope design are to use the combination of slope performance, rock strength and geological structure to formulate slope designs. At Mt Rawdon those factors are:

- A high strength rock mass, which is generally broadly jointed, but with multiple structural orientations.

- Many flat dipping structures.

- Many larger scale intersecting faults, shears, dykes and contacts (Figure 2), which are too flat to eliminate with any 'economic' slope design.

In combination, these factors dictated the focus for the geotechnical slope design studies, which comprised of four elements:

- The detailed bench slope profile. 
- Blasting.

- Major structures intersecting with intermediate structures.

- Groundwater pressures and major structures.

It also needed to be recognised that two of these, blasting and groundwater pressures, are, to a significant extent, controllable in the open pit context. The potential adverse outcomes from intersecting major and intermediate structures required ongoing management, with mapping, modelling and rock support.

\subsection{Rock intact and mass properties}

The mean intact uniaxial compressive strengths for all rocks are in the range from 65 to $150 \mathrm{MPa}$. The mean geological strength index (GSI) for the main rock types are in the range from 44 to 64 , reflecting the high quality of the rock mass. However, for some of the dyke materials and the surrounding rock mass, which is variably sheared, the GSI is in the range from 25 to 32 . Overall, this results in a high to very high strength rock mass, which is broadly jointed and intersected by some narrow zones and some pockets of very poor rock mass.

\subsection{Role of structure}

\subsubsection{Introduction}

The structural model is of major importance for understanding the pit wall performance at Mt Rawdon. Structural modelling is an ongoing process carried out by site mine geologists and geotechnical engineers using a combination of wall mapping and drilling information. However, model uncertainties remain where structures have to be interpolated at depth, as well as, at complex intersections of stratigraphic markers in boreholes and, for which, further drilling would not reduce these uncertainties.

The major structures are fundamental because they provide the architecture upon which the intermediate and lower order structures sit. However, like most open pit structural geological models there inevitably seems to be gaps outside the pit and a propensity for radial structures, centred on the open pit itself. This is partly evident in Figure 3.

The pit is approximately rectangular in plan, Figure 3 , skewed slightly west of north. Although it may be confusing when viewing stereonets, the convention adopted in this paper is to simply refer to overall wall locations; West, East, South, North and Northwest.

\subsubsection{Mapping techniques}

The geological mapping at Mt Rawdon has comprised of:

- Rigorous geotechnical line mapping (mainly in the earlier years of pit development and hence not comprehensive coverage).

- SiroVision mapping of most walls.

- Selected mapping of exposed structures in the pit walls, mainly in the southern portion of the current pit.

- Large scale geological mapping, which is still being upgraded during the course of the slope design studies.

The first major focus for the recent geotechnical studies was on evaluation and validation of these separate databases. That process, which was undertaken by comprehensive in-pit comparison, showed:

- The geotechnical line mapping dataset provided the best match with actual structure for all pit walls.

- The selected mapping assisted in filling gaps in-pit coverage, but appeared to contain a number of sampling and measurement biases. 
- The SiroVision data did not match the in-pit structure evident in the pit walls nor the other structure databases. Furthermore it was a very poor indicator of actual slope performance.

Based on this, the design structure dataset was the geotechnical line mapping. It was also concluded, based on the detailed calibration of pit wall performance that joints could be ignored and the 'design' structure set was intermediate scale faults and shears.

\subsubsection{West Wall}

The West Wall is located predominantly within Dacite with a major Rhyolite Dyke with an east-west strike and a flat dip towards the north. Figure 4 shows the condition of the wall and the corresponding equal area projection. The lines are approximate planes representing wall orientations and, the arrows, wall dip directions. The dominant pattern evident is a series of semi-continuous structures dipping north, sub-parallel to the Rhyolite dyke, 10 to $50^{\circ}$ towards the north. A second set of more widely spaced structures dip south, 10 to $20^{\circ}$. Although the moderate to flat dipping defect sets are oriented favourably for this wall as evident on both the photo and stereonet, there is considerable berm crest loss. This is the main slope design consideration for this wall in this rock mass. The berm crest loss takes the form of triangular and tetrahedral wedges and these are mostly scaled during mining.
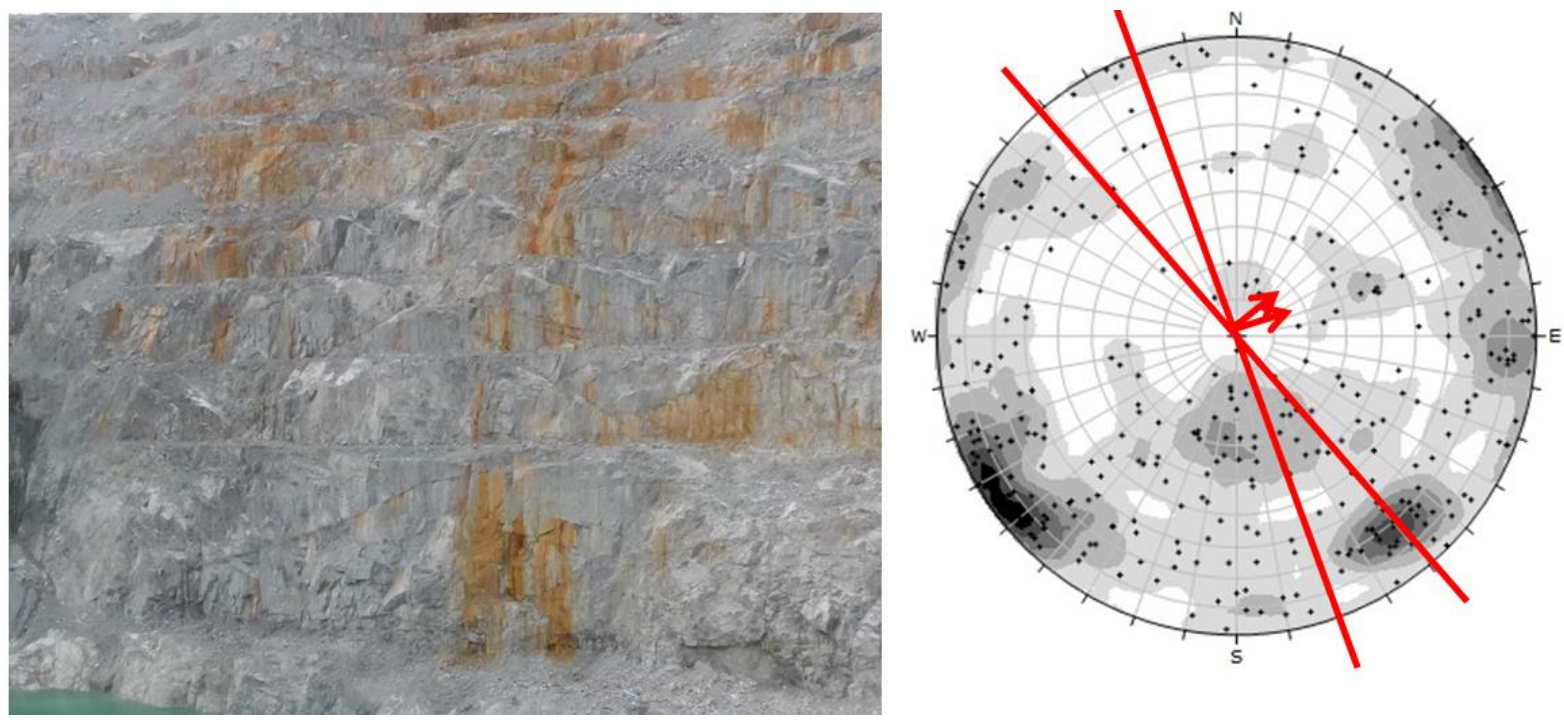

Figure 4 A photo illustrating the condition of a section of the West Wall and stereonet of intermediate scale faults and shears. The lines are schematic planes representing the pit wall orientations

Neither kinematic nor probabilistic analysis of bench slope angles were carried out for the design, and vertical bench slopes were adopted.

\subsubsection{East Wall}

East wall is located predominantly in Dacite. Figure 5 shows the wall condition and the corresponding equal area projection. On a larger scale, Figure 2, the wall contains multiple major structure orientations, however, overall the pit wall is in a very good condition with only minor berm crest loss. There are a number of weakly developed minor defect sets dipping at 15 to $50^{\circ}$ in orientations that could contribute to berm crest loss (Figure 5), however the defects are too small a population to control performance. Some local adverse stability conditions have developed where the major sub-vertical structures intersect intermediate faults and shears leading to local block toppling failures and sliding failures, but these mainly occurred during and after rain events. 

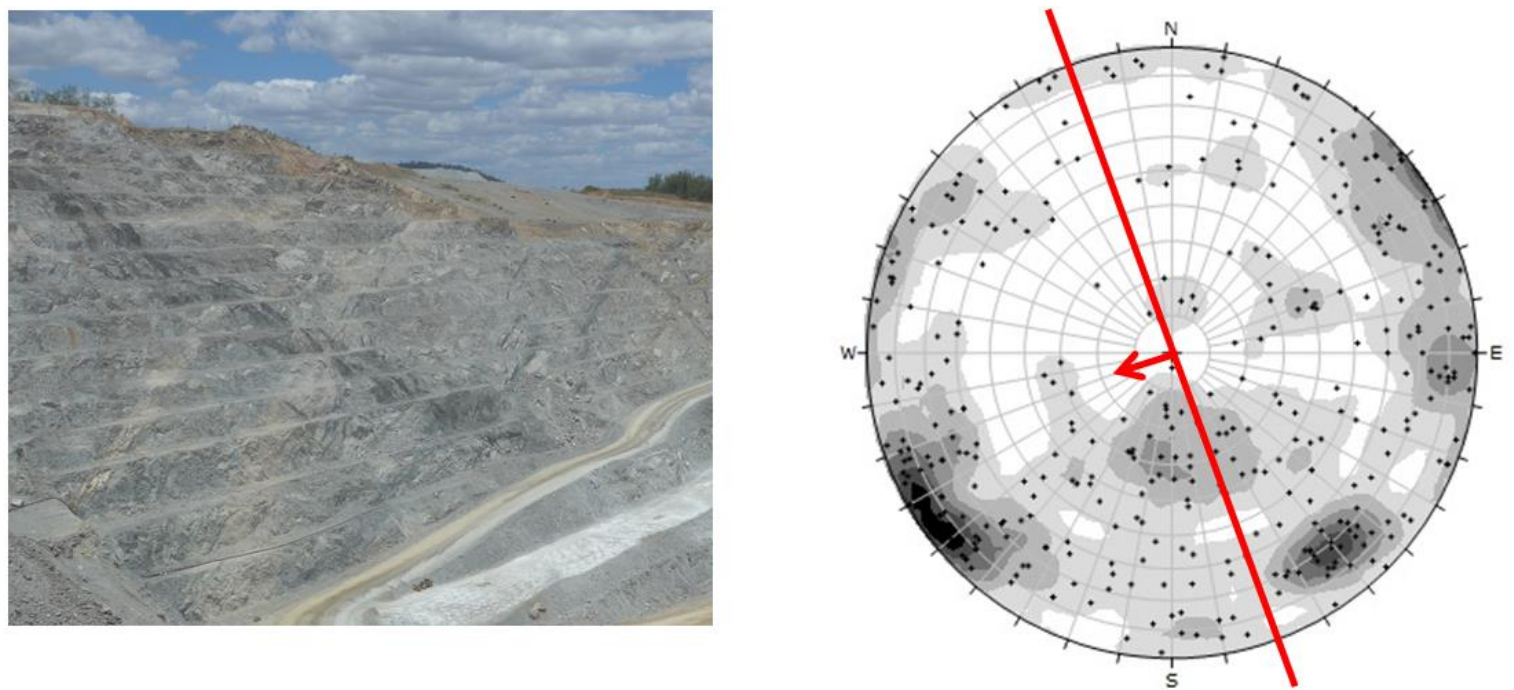

Figure 5 A photo illustrating the condition of a section of the East Wall and stereonet of intermediate scale faults and shears. The line is a schematic plane representing the wall orientation

Neither kinematic nor probabilistic analysis of bench slope angles were carried out for the design, and vertical bench slopes were adopted. However, because of the large scale structures, the main slope design consideration for this wall is large scale instability driven by ground water pressures.

\subsubsection{South Wall}

The structural patterns for intermediate scale faults and shears indicate the South Wall will experience major stability problems as shown in Figure 6 . There are multiple defects dipping directly out of the face between 15 and $40^{\circ}$, with potential for numerous bench and intermediate scale wedge and planar sliding failures.
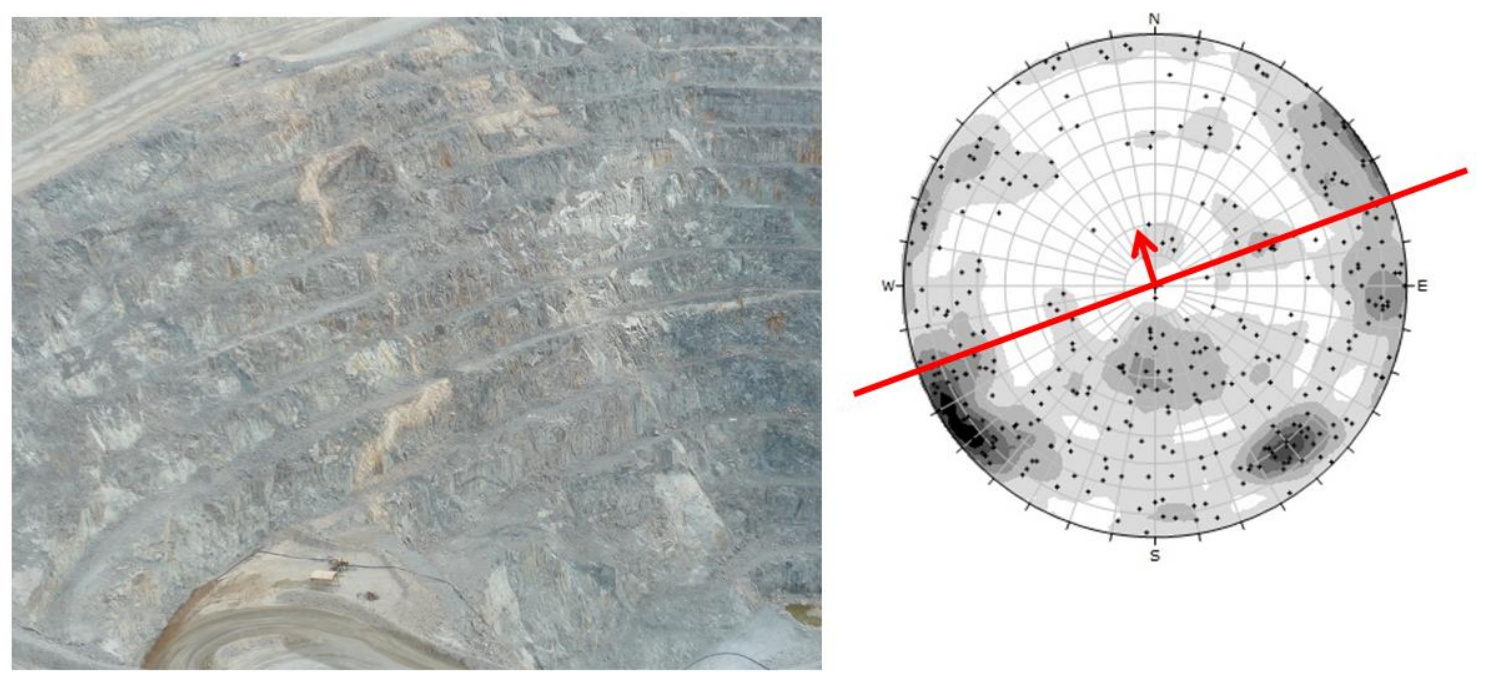

Figure 6 A photo illustrating the condition of the South Wall and stereonet of intermediate scale faults and shears. The line is a schematic plane representing the wall orientation

However, on review, whilst the structural pattern was present, the design dataset; is geotechnical line mapping, which was mainly collected at higher elevations and, mostly, further north of this wall. Hence, most of the more continuous structures (as shown in the upper right side of the photo in Figure 4), occur at higher elevations than the South Wall. Consequently, only isolated local sliding is expected, which accords with the performance, and these have been manageable to date.

Neither kinematic nor probabilistic analysis of bench slope angles were carried out for the design, and vertical bench slopes were adopted. 


\subsubsection{North Wall}

The North Wall is predominantly within volcaniclastics with Trachyte Dyke intrusions throughout. Figure 7 shows the condition of the wall and the corresponding equal area projection. The lines are approximate planes representing wall orientations and, the arrows, wall dip directions. Figure 7 shows structure continuity over four benches and there is a major berm crest loss. The other contributing factor is the sheared character of the rock mass, which is most probably associated with the dyke intrusions, resulting in increased structure intersections and a high frequency of defect infill. There has also been one inter-ramp scale failure, the only significant failure to date in the current pit. The main slope design considerations for this wall, in this rock mass, are berm loss and potential for inter-ramp structural failures.

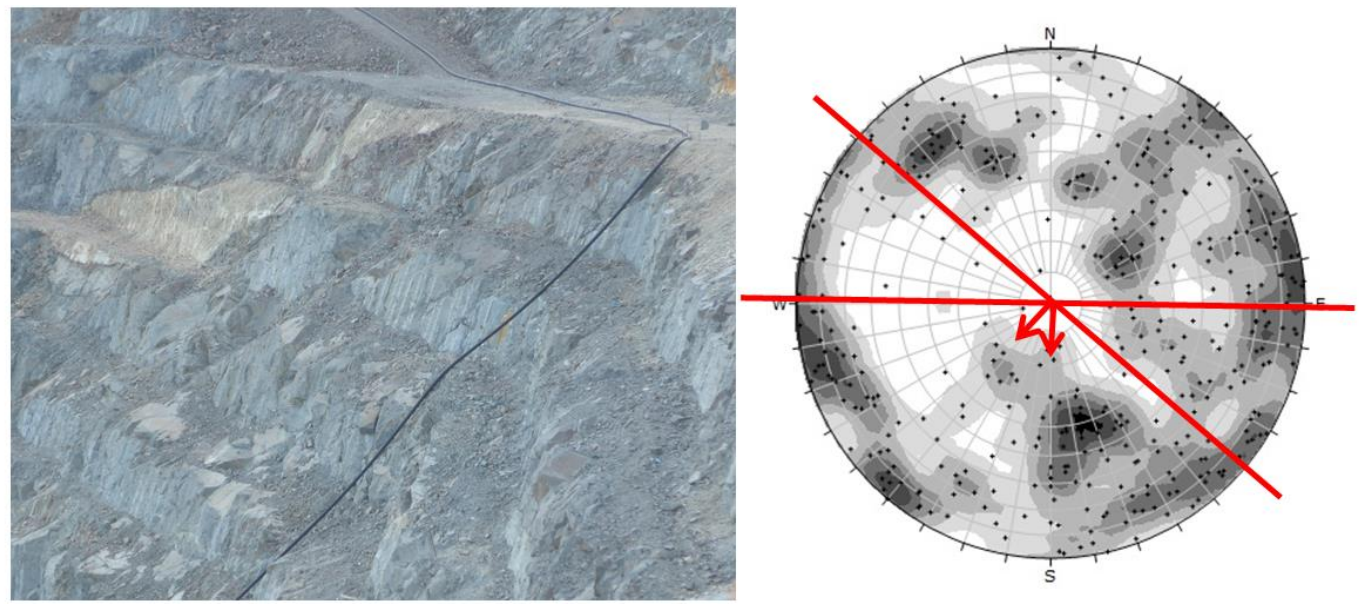

Figure 7 A photo illustrating the condition of the North Wall and stereonet of intermediate scale faults and shears. The lines area schematic planes representing the wall orientations

The North Wall has been found to be the most difficult to manage. There is high likelihood of crest loss and significant berm loss due to structures leading to minimal berm widths and compromised catch capacity. Cable bolting is planned to control the crests and the predicted planar and wedge failures.

\subsubsection{Northwest Wall}

Figure 8 shows the condition of the Northwest Wall with the corresponding equal area projection. Although this is only a short section of wall, in the pit, it is included here as a point of difference with structural patterns and slope performance. As indicated in Figure 8 , there are no adversely oriented structure sets and the berms and berm crests are all intact.
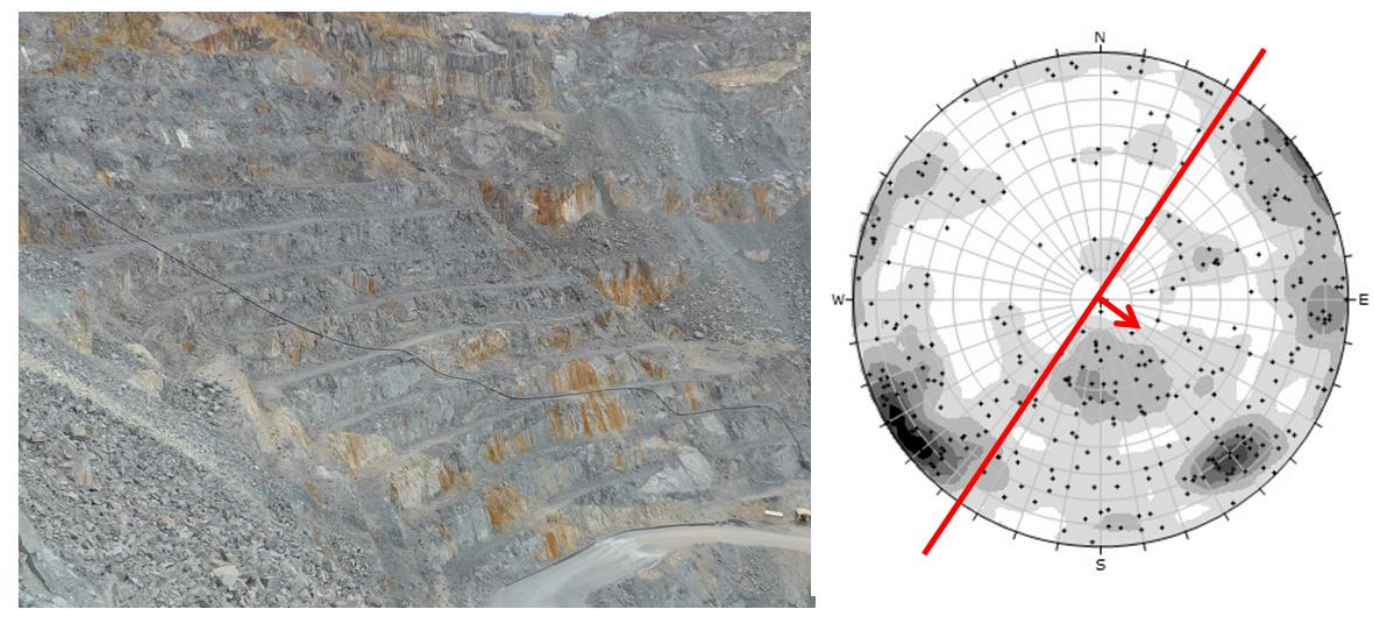

Figure 8 A photo illustrating the condition of the Northwest Wall and stereonet of intermediate scale faults and shears. The line is a schematic plane representing the wall orientations 


\section{$5 \quad$ Overall slope performance}

\subsection{Introduction}

Overall, the stability performance of the current pit has been sound with only two significant rockfalls, a 4 to 5 bench scale non-daylighting wedge failure of the Northeast Wall, which was triggered by blasting, and a batter scale planar failure on the East Wall, triggered by rainfall.

However, the real slope design challenge at Mt Rawdon is developing a bench and berm profile that allows the good rock mass quality and high strength to be exploited with steep inter-ramp slopes, without compromising safety.

\subsection{Bench performance trials}

Figure 9 shows the results of various bench slope trials on the West Wall. The geology, geotechnical conditions and structure are the same in all four benches. The trial results merely reflect the influence of:

- The bench face slope angle in relation to the dip of the structures.

- Blasting.

- The presence of and, hence, the frequency of berms.

These act to form free faces allowing displacement and failure along structures.

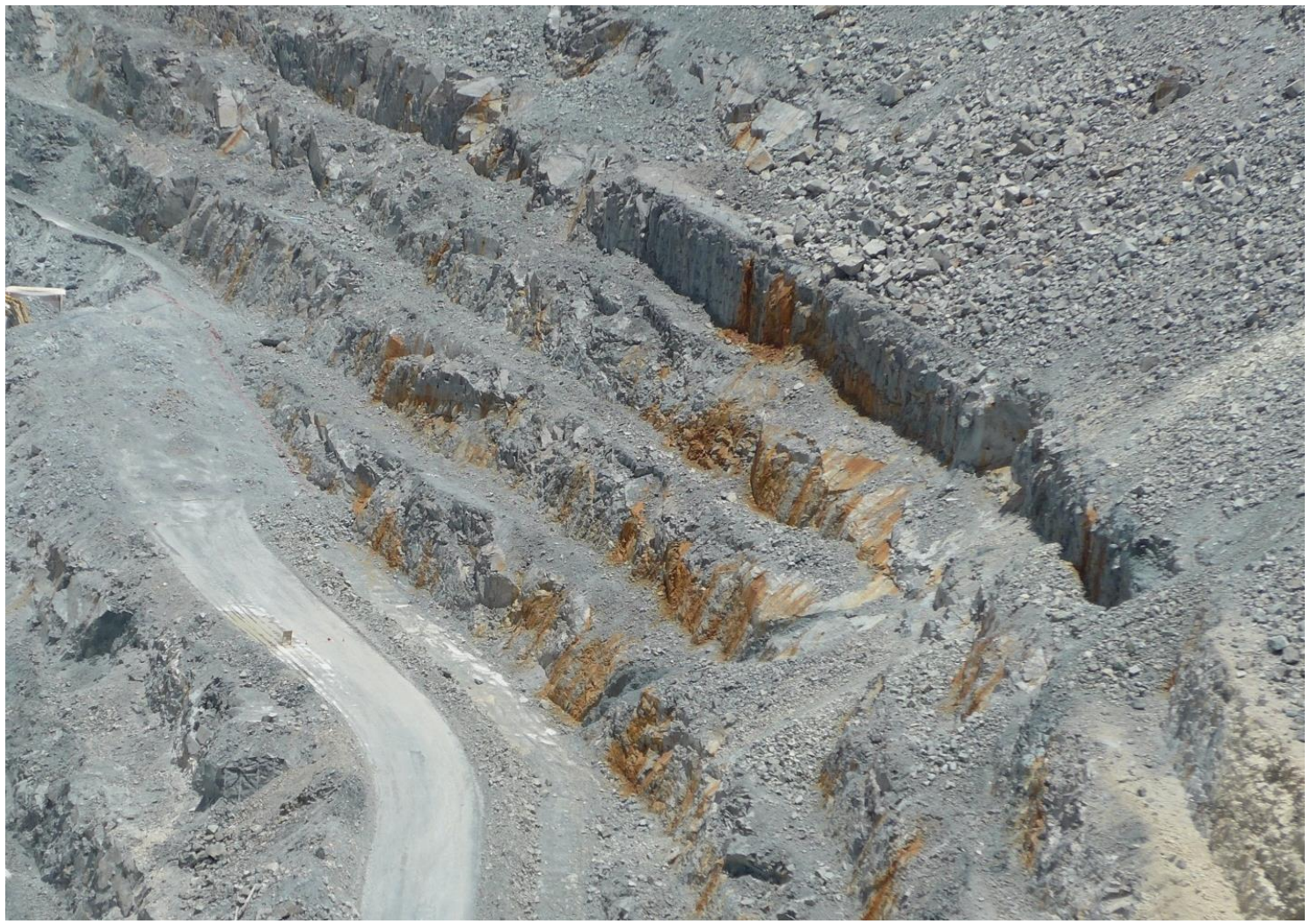

Figure 9 A view looking south of the West Wall showing bench performance trials

Figure 10 shows the interaction between these factors. As the bench face angle approaches the dip of structures in the wall then the blasting gases and energy is preferentially directed along the pre-existing geological structure planes. This occurs even if pre-splits have been used. 


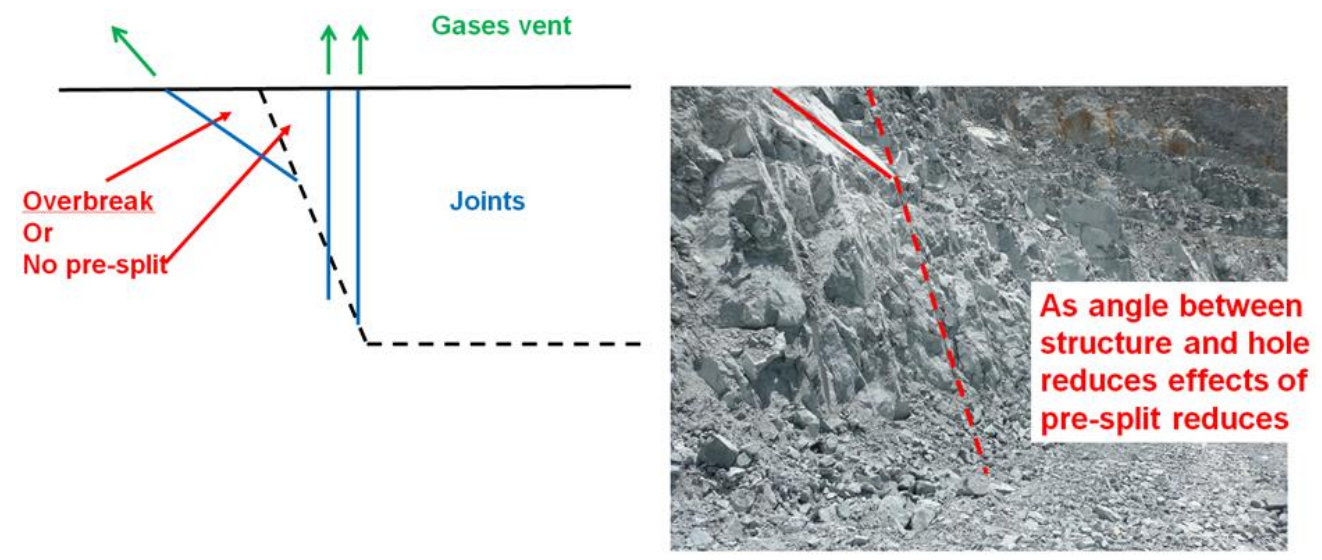

Figure 10 Illustration of the interaction between final wall blasting angle, rock structure and wall performance

The result is a slope performance bias that merely reflects the interaction of the design with the rock mass, not the optimum bench and berm geometry. This is also, in large part, why the SiroVision results were poor. The remote capturing of structural information oversampled the structures along which the benches had failed, and not the real population of defects in the wall.

\subsection{Overall slope monitoring}

Prisms are located on all pit walls and are monitored by an automated reading and alarm system. Slope movement monitoring is supplemented by regulated inspections. This monitoring has not shown any significant overall movements to date, with the exception of the East Wall. The East Wall has shown creep movement, for the past two and a half years. The displacements are a combination of structure and groundwater pressures. The small failure on the East Wall, above the haul road, is believed to be a manifestation of that movement.

The cumulative displacements are in the range of $150 \mathrm{~mm}$ over the two and a half year period. The highly fractured rock mass is now more sensitive to rainfall, Figure 11 . As previously noted, the rock mass is of low permeability, however, there are abundant continuous low strength structures present, Figure 2 . These structures allow strains within the rock mass, due to mining, to be concentrated along the structures, causing dilation and increased sensitivity to transient rainfall loading events.

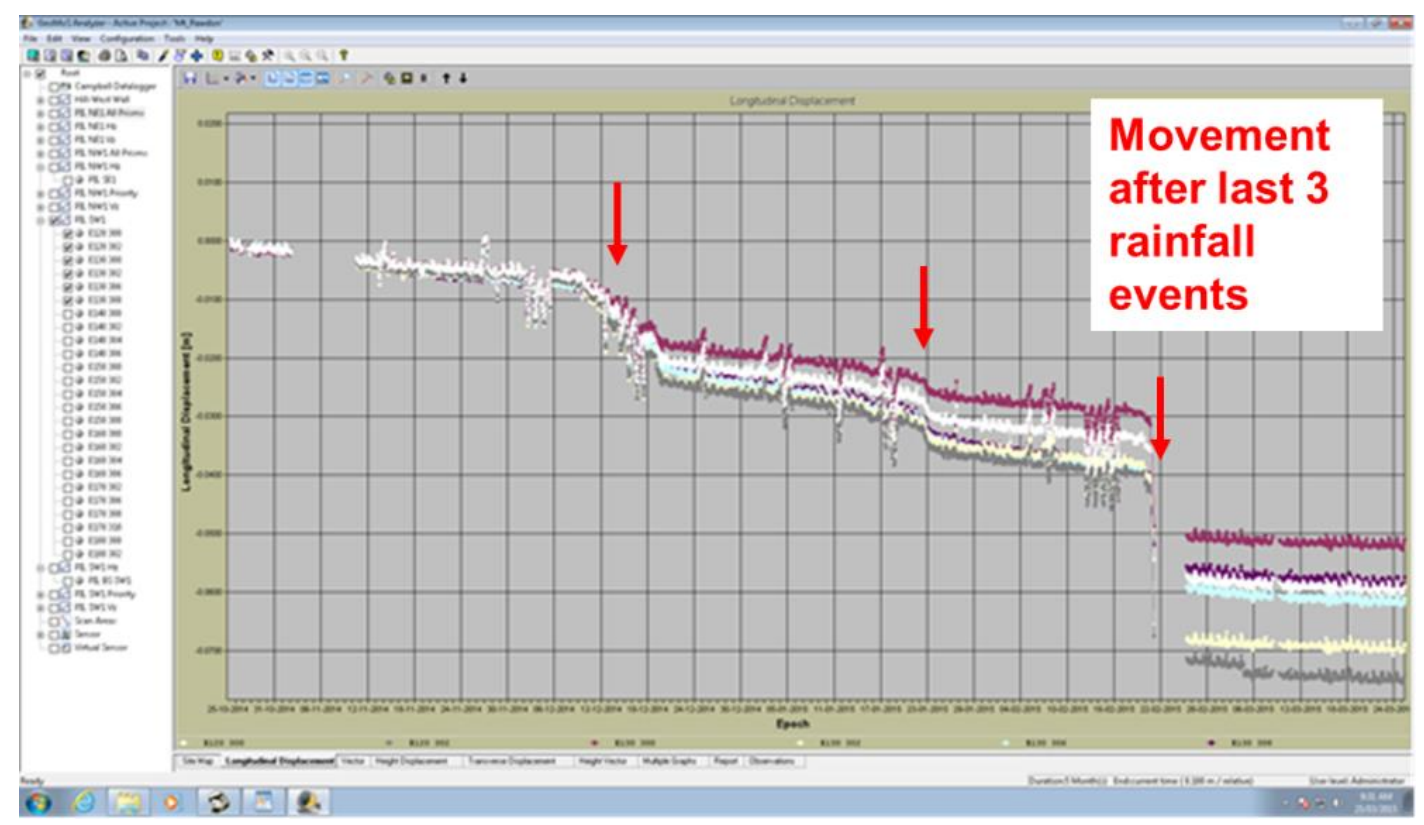

Figure 11 Monitoring data for the East Wall over a period of two and a half years. Arrows depict onset of wet weather events 


\section{$6 \quad$ Pit design strategy}

\subsection{Previous slope designs}

Mining at Mt Rawdon is based on conventional drill and blast, excavator load and truck haulage. Pit walls are developed in conventional batter-berm configuration. External and internal geotechnical advice had highlighted that mining of the Mt Rawdon orebody, with the complex structural conditions, presented significant geotechnical risks that were not fully understood. Initially the mining was done in $15 \mathrm{~m}$ benches, at $75^{\circ}$ and $10 \mathrm{~m}$ wide berms. This configuration resulted in considerable crest loss and with the planned inter-ramp slopes of $56^{\circ}$. This also resulted in a high probability of rockfalls as the pit was deepened. Risk assessments confirmed that establishing and maintaining berms was going to be a challenge in many areas of the pit. The high rockfall risk resulted from the inherent structural conditions, coupled with the extensive crest loss, Figure 9 , and loss of effective catch capacity.

\subsection{Revised designs}

Because reasonably flat benches had been used, the previous slope designs, at Mt Rawdon, resulted in berm widths that were too narrow to maximise inter-ramp slopes. As a consequence, the following practical issues arose.

- The bench crests are lost due to blasting, because the flatter lying joints lie close to the blasthole inclination and blast gases are vented up the joints.

- Because of this, the narrow berms then lose some of their effective storage for rockfall.

- The overall result is a loss of effective catch capacity at the inter-ramp slope scale.

Given this set of geotechnical conditions and practical performance, the challenge was what changes can be made to achieve a better overall outcome? The basic slope design unit is the bench height, bench angle and berm width. All of these inter-relate and contribute to a practical, safe and economic design. The previous designs used bench angles of $75^{\circ}$. However, the detailed review of the structural data showed most of the joints that have contributed to poor bench performance had inclinations from 30 to $65^{\circ}$. Hence there was no data to support a $75^{\circ}$ bench angle, compared to say 80,85 or $90^{\circ}$ bench faces. This conclusion was clearly supported by the performance of the trials (Figure 9).

Vertical benches have also been used by one of the authors in appropriate geotechnical settings for more than 30 years. Experience has also shown that vertical benches make all aspects of final wall blasting easier to implement and manage. This is because the pre-split drill set up is simpler and drill control is improved resulting in straighter pre-split holes. However, one of the potential concerns with vertical benches is the risk of failure on inclined joints. The authors have considered this situation and elected to trial $15 \mathrm{~m}$ high benches, which are mined in $7.5 \mathrm{~m}$ lifts, in order to minimise local exposure from rock blocks during mining.

Based on successful trials of this design, the slopes design was further optimised. Because of the strength and character of the rock mass, and the structural patterns, double benching was adopted in order to increase the resultant catch berm widths. Double benching will result in an 18 to $20 \mathrm{~m}$ wide berm. Even with significant crest loss, due to the flat joints, the remnant catch capacity is estimated at around 12 to $14 \mathrm{~m}$. This is in excess of the normal operating tolerances for a $30 \mathrm{~m}$ high bench. The recommended design comprises of:

- Two $15 \mathrm{~m}$ benches at $90^{\circ}$.

- A small $2 \mathrm{~m}$ wide lip between the upper and lower $15 \mathrm{~m}$; resulting in adequate standoff for the drilling rigs.

- An $18 \mathrm{~m}$ wide berm.

- Pre-splitting the upper bench only. 
- A bund when drilling the lower $15 \mathrm{~m}$ bench together with modified blasthole spacing, orientation and charging.

- Adequate breakage of the rock mass.

- Ensuring toe is minimised.

The resultant inter-ramp slopes are now in the range of 60 to $64^{\circ}$ in many areas of the pit.

\section{Conclusion}

Mt Rawdon pit wall design parameters have been derived in an iterative design assessment process. The fundamental elements of that process were developed specifically for the Mt Rawdon conditions and do not follow a conventional slope design process. The result has been to achieve both a safer and steeper overall pit design. The new designs have been successfully trialled and have now been incorporated into the latest pit design. This result has been achieved in difficult geotechnical conditions. The fundamental keys of the process, and its success, are:

- Understanding the overall geotechnical character of the rock mass.

- Review and in-pit validation of the different structure data sets.

- Careful selection of the appropriate structure set for slope design in each pit wall sector.

- Understanding how each of the different datasets can contribute to slope performance at all scales.

- Understanding the interaction between rock structure and blasting.

- Formulating a design that incorporates final wall blasting practices to achieve slope designs that are not only safer, but steeper.

\section{References}

Angus, M 1999, The Mount Rawdon gold deposit, Southeast Queensland.

Brooker, MR 1991, 'Geology, Alteration, and Mineralisation of the Mt Rawdon diatreme-hosted gold deposit', MSc Thesis dissertation, James Cook University.

Brooker, M \& Jaireth, S 1995, 'Mount Rawdon, Southeast Queensland, Australia - a diatreme-hosted gold-silver deposit', Economic Geology, vol. 90, pp. 1799-1817.

Cayzer, RA \& Leckie, JF 1987, 'Mt Rawdon: exploration of a bulk low-grade gold deposit', Papers Department of Geology University of Queensland, vol. 12, no. 1, pp. 85-99.

Gallo, JB, Mustard, H \& Taylor, S 1990, 'Mount Rawdon Gold Deposit', in FE Hughes (ed.), Geology of the Mineral Deposits of Australia and Papua New Guinea, The AusIMM, pp. 1505-1507.

Harris, A 2010, Geology of the Mt Rawdon Au mine: preliminary observations, unpublished report, p. 17.

Hewett, D 1984, 'The Mt Rawdon Gold Prospect', MSc Thesis Dissertation, James Cook University, p. 36. 